\title{
Referenciais da pedagogia do esporte e as dimensões dos conteúdos: interfaces teóricas e aplicadas ${ }^{1}$
}

\section{Referential of the sport pedagogy and the contents dimensions: theoretical and applied interfaces}

\section{Referenciales de la pedagogía del deporte y las dimensiones de los contenidos: interfaces teóricas y aplicadas}

(iD) Thiago José Leonardi Universidade Federal do Rio Grande do Sul, Porto Alegre, Rio Grande do Sul, Brasil E-mail: thiago.leonardi@ufrgs.br

(iD) Artur Goulart Berger Universidade Federal do Rio Grande do Sul, Porto Alegre, Rio Grande do Sul, Brasil E-mail: arturgberger@gmail.com

iD@ Guy Ginciene Universidade Federal do Rio Grande do Sul, Porto Alegre, Rio Grande do Sul, Brasil E-mail: guy.ginciene@ufrgs.br

iD André Luís Ruggiero Barroso Centro Universitário de Jaguariúna, Jaguariúna, São Paulo, Brasil E-mail: andrebarroso155@gmail.com

iD (9) Roberto Rodrigues Paes Universidade Estadual de Campinas, Campinas, São Paulo, Brasil E-mail: paes@unicamp.br

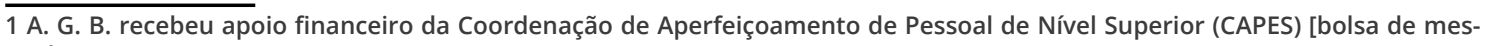
trado]. 
Resumo: Este ensaio teve como objetivo dialogar acerca das interfaces entre os referenciais da Pedagogia do Esporte e as dimensões dos conteúdos, buscando apresentar a aplicação prática com base em subsídio teórico. Resgatou-se que, embora tenham surgido a partir da escola, os referenciais nasceram de forma específica nas reflexões acerca do esporte e as dimensões advêm da grande área da educação. Destaca-se que referenciais e dimensões dos conteúdos, embora diferentes, são complementares e intrinsecamente interligados, podendo estar presentes em diferentes cenários de atuação, aplicados a diferentes personagens e interligados a diferentes conteúdos, cabendo ao agente pedagógico a escolha assertiva da ênfase a ser dada de acordo com seu planejamento.

Palavras-chave: Esporte. Pedagogia do Esporte. Dimensões dos Conteúdos.

Abstract: This essay aimed to dialogue about the interfaces between the referential of the Sport Pedagogy and the contents dimensions, seeking to present practical application based on theoretical support. It was rescued that although they emerged from school, the referential were born specifically in the reflections about sport and the dimensions come from the large area of education. It is noteworthy that referential and dimensions of the contents, although different, are complementary and intrinsically interconnected, and may be present in different scenarios of action, applied to different characters and interconnected to different contents, and the pedagogical agent is responsible for the assertive choice of the objective, content and emphasis to be given according to their planning.

Keywords: Sport. Sport Pedagogy. Contents dimensions.

Resumen: Este ensayo tuvo como objetivo dialogar sobre las interfaces entre los referenciales de la Pedagogía del Deporte y las dimensiones de los contenidos, buscando presentar una aplicación práctica basada en el apoyo teórico. Se rescató que los referenciales nacieron específicamente en las reflexiones sobre el deporte y las dimensiones provienen de la gran área de la educación. Cabe destacar que los referenciales y dimensiones de los contenidos, aunque diferentes, son 
complementarias e intrínsecamente interconectadas, y pueden estar presentes en diferentes escenarios, aplicados a diferentes personajes e interconectados a diferentes contenidos, y el agente pedagógico es responsable de la elección asertiva del objetivo, contenido y énfasis que se debe dar de acuerdo a su planeamiento

Palabras Clave: Deporte. Pedagogía del Deporte. Dimensiones de los contenidos.

Submetido em: 19-05-2021

Aceito em: 30-06-2021

"Não basta ensinar aos alunos a técnica dos movimentos, as habilidades básicas ou, mesmo, as capacidades físicas. É preciso ir além e ensinar o contexto em que se apresentam as habilidades ensinadas, integrando o aluno na esfera da sua cultura corporal" (Suraya Cristina Darido). 
Referenciais da pedagogia do esporte e as dimensões dos conteúdos: interfaces teóricas... Thiago José Leonardi • Artur Goulart Berger • Guy Ginciene • André Luís Ruggiero Barroso • Roberto Rodrigues Paes

\section{Introdução}

Um dos maiores fenômenos socioculturais contemporâneos é o esporte (GALATTI, 2010), considerado um dos elementos centrais da cultura nacional (PAES, 1996) e um patrimônio da humanidade (REVERDITO; SCAGLIA; PAES, 2009). A relevância do esporte se ampliou (e se amplia) na sociedade (ELIAS; DUNNING, 1992), exigindo das Ciências do Esporte, desde a década de 1960 (GUTTMANN, 1978), atenção às práticas esportivas como ferramenta educacional, buscando ampliar a compreensão e interpretar a complexidade que envolve as práticas corporais na sociedade (LEONARDI, BERGER, REVERDITO, 2019). Contemporaneamente, compreendemos que o esporte é um fenômeno sociocultural presente em diferentes cenários (escola, clube, prefeitura, ONG, entre outros) que permite aos seus participantes dar múltiplos sentidos e significados a essa prática (GALATTI et al., 2017). Além disso, o esporte pode ser um agente transformador na sociedade, ao passo que também pode contribuir para o desenvolvimento integral do indivíduo (MEDINA, 1983; LEONARDI et al., 2014).

A Pedagogia do Esporte é uma área das Ciências do Esporte responsável por investigar a intencionalidade e a funcionalidade da atuação pedagógica (FERREIRA, 2009; LEONARDI; BERGER; REVERDITO, 2019), a qual perpassa o processo de planejamento, organização, sistematização, aplicação e avaliação de procedimentos pedagógicos que visam o processo de ensino, vivência, aprendizagem e treinamento esportivo (GALATTI et al., 2014). Nesse sentido, uma das etapas salutares desse processo é a definição e organização dos conteúdos a serem desenvolvidos no decorrer de um ciclo de aulas ou treinos.

Partindo do pressuposto - parafraseando Freire (2002) - de que é preciso ensinar bem o esporte, ensinar bem a todos, ensinar a gostar de esporte e ensinar mais do que esporte, há na literatura uma proposta para auxiliar professores(as)/treinadores(as) a pensarem nos conteúdos a serem ministrados em aula ou treino 
Referenciais da pedagogia do esporte e as dimensões dos conteúdos: interfaces teóricas... Thiago José Leonardi • Artur Goulart Berger • Guy Ginciene • André Luís Ruggiero Barroso • Roberto Rodrigues Paes

a partir de três referenciais: técnico-tático, socioeducativo e histórico-cultural (MACHADO et al., 2014). Essa proposta ampliou o conceito de ensino dos esportes associado apenas à prática do movimento, corroborando a premissa de buscar contribuir para o desenvolvimento integral do indivíduo e, ao mesmo tempo, ensinar o esporte a partir de seu significado contemporâneo, ao associar a prática do jogo (referencial técnico-tático) com condutas e formas de comportamento (socioeducativo) e a compreensão da evolução e valorização cultural da modalidade (histórico-cultural). Esses referenciais, portanto, no âmago da Pedagogia do Esporte, deveriam se fazer presentes em todos os cenários de prática esportiva com proposta educacional e formativa (MACHADO et al., 2014; LEONARDI et al., 2017), em ambientes de educação formal, não-formal e informal (PAES, 1996).

No cenário da educação formal, o esporte é um dos conteúdos a serem desenvolvidos no componente curricular Educação Física (DARIDO, 2005). Do ponto de vista legal, a Lei 9.394/96 (BRASIL, 1996), seguida pelos Parâmetros Curriculares Nacionais (BRASIL, 1997), sinalizou novos conteúdos a serem abordados na Educação Física Escolar para além do esporte, dentre eles o jogo, a ginástica, a luta e a dança. Atualmente, está em vigência no Brasil a Base Nacional Comum Curricular (BRASIL, 2018), que propõe uma organização dos diferentes conteúdos ao longo dos ciclos de ensino, organizando a Educação Física em seis unidades temáticas (Esporte, Brincadeiras e Jogos, Danças, Lutas, Ginástica e Práticas Corporais de Aventura), dando foco para a cultura corporal de movimento e ressignificação dessas práticas na sociedade por parte dos alunos. A unidade Esporte, conteúdo foco de estudo neste ensaio, está organizada na Base Nacional Comum Curricular (BRASIL, 2018) em sete categorias (Marca, Precisão, Técnico-combinatório, Rede/quadra dividida e Parede de Rebote, Invasão ou Territorial, Campo e Taco e Combate), estruturadas com base na lógica interna das modalidades, conceituada como "as características de desempenho exigidas pelas situações motoras criadas pelos diferentes tipos de esportes" (GONZÁLEZ, 2006, p. 90). 
Referenciais da pedagogia do esporte e as dimensões dos conteúdos: interfaces teóricas... Thiago José Leonardi • Artur Goulart Berger • Guy Ginciene • André Luís Ruggiero Barroso • Roberto Rodrigues Paes

Ainda no contexto escolar, Paes (1996), sustentado pelos conceitos da Pedagogia do Esporte, comenta que por suas características transformadoras, o esporte se constitui como um meio para o professor intervir, objetivando o desenvolvimento do aluno e transformações sociais. Uma das proposições teóricas para se pensar o ensino do esporte na escola, na tentativa de ampliar a maneira como esse conteúdo é abordado nas aulas de Educação Física, foi exposto por Barroso e Darido (2009), os quais, alinhados com as propostas dos Parâmetros Curriculares Nacionais (BRASIL, 1997) e de autores como Zabala (1998) e Coll et al. (2000), sinalizaram que o conteúdo esportivo deveria ser abordado na escola a partir de três dimensões: procedimental (o que se deve saber fazer), conceitual (o que se deve saber) e atitudinal (como se deve ser). Barroso e Darido (2009) endossaram a crítica à manifestação preponderante da dimensão procedimental dos conteúdos esportivos nas aulas de Educação Física, em detrimento de pouca ênfase nas dimensões conceitual e atitudinal. Porém, tratar dos conteúdos a partir de suas dimensões não é uma prática que se limita ao ambiente escolar, visto que Programas como os do Segundo Tempo, por exemplo, abordam as três dimensões junto às práticas de esporte, ginástica, dança e lutas em ambientes de ensino considerados como não formais (OLIVEIRA et al., 2011).

Contudo, quais as interlocuções que podem ser feitas entre os referenciais da Pedagogia do Esporte e as dimensões dos conteúdos? São eles propostas semelhantes ou podemos interpretá-los como conceitos distintos, porém interligados? Nesse sentido, este ensaio se propõe a dialogar acerca das interfaces entre ambos os conceitos, buscando trazer exemplos práticos que auxiliem professores e pesquisadores a visualizá-los no contexto aplicado, com base em subsídio teórico. Para tanto, este estudo adotou elementos característicos da pesquisa bibliográfica por meio da técnica de revisão bibliográfica (SEVERINO, 2000). 
Referenciais da pedagogia do esporte e as dimensões dos conteúdos: interfaces teóricas... Thiago José Leonardi • Artur Goulart Berger • Guy Ginciene • André Luís Ruggiero Barroso • Roberto Rodrigues Paes

\section{Referenciais da pedagogia do esporte}

A Pedagogia do Esporte, enquanto área das Ciências do Esporte, transcende a preocupação de "apenas" ensinar esporte, buscando orientar, organizar, sistematizar, refletir, avaliar e criticar os procedimentos pedagógicos assumidos pelo agente pedagógico (professor ou treinador), com a intenção de garantir a intencionalidade daquilo que se ensina ou treina, tendo o aluno como sujeito central desse processo (REVERDITO; SCAGLIA; PAES, 2009; GALATTI et al., 2014). Nesse sentido, notamos a preocupação com o ser humano envolvido na prática e isso implica compreendê-lo de maneira integral (LEONARDI et al., 2014).

Para isso, é preciso considerar o esporte a partir de um novo paradigma, inserido na sociedade contemporânea, em que os seus personagens podem estar em diferentes cenários, praticando diferentes modalidades com diversos objetivos, sentidos e possibilidades (GALATTI et al., 2014). Isso implica compreender a atuação pedagógica de professores e treinadores para além dos elementos técnicos e/ou táticos de determinada modalidade, mas, sobretudo, enquanto agentes pedagógicos, que podem contribuir para a educação e transformação de seres humanos que serão agentes na sociedade (PAES, 1996; SCAGLIA, 1999). Assim, coube à Pedagogia do Esporte elaborar pressupostos do que seria importante desenvolver no processo de ensino, vivência, aprendizagem e treinamento esportivo: surgiram os referenciais.

Os referenciais podem, portanto, ser definidos como uma referência para a futura organização dos conteúdos (ou conjunto de conhecimentos) que, sustentados teoricamente, precisariam ser apresentados e desenvolvidos com alunos ou atletas durante a sua vivência e aprendizagem (ou treinamento) esportivo. Os referenciais da Pedagogia do Esporte foram propostos inicialmente por Paes (1996), quando ele notou maior preocupação pelo ensino das questões técnicas e táticas das modalidades no contexto escolar, ao que ele chamou de "referencial metodológico". Em sua pes- 
Referenciais da pedagogia do esporte e as dimensões dos conteúdos: interfaces teóricas... Thiago José Leonardi • Artur Goulart Berger • Guy Ginciene • André Luís Ruggiero Barroso • Roberto Rodrigues Paes

quisa, Paes (1996) defendia que o esporte também poderia ser um facilitador para aprendizagem educacional e formação humana, ao que chamou de "referencial socioeducativo". A proposta, portanto, fazia emergir a reflexão acerca do que deveria ser ensinado no contexto esportivo, e, naquele momento, apresentou propostas de conteúdos, à luz dos referenciais, a serem desenvolvidos para o ensino do esporte nas diferentes séries do ensino fundamental II (atualmente, do $6^{\circ}$ ao $9^{\circ}$ ano).

Com o avanço das pesquisas em Pedagogia do Esporte e a intenção de balizar uma prática pedagógica que

contribua não somente com o desenvolvimento motor, [mas também na direção de] uma formação plena de seus praticantes em seus aspectos motores, físicos, emocionais, sociais, afetivos, cognitivos e culturais (MACHADO, 2012, p. 102).

Os conteúdos, na Pedagogia do Esporte, passaram a ser organizados com base em três referenciais: o referencial técnico-tático (nova denominação para o "referencial metodológico"), que orienta o desenvolvimento de questões motoras, físicas, fundamentos e sistemas de cada modalidade; o referencial socioeducativo, que compreende valores, modos de comportamento e o estímulo à cidadania, e o histórico-cultural, responsável por apresentar a história do esporte e das modalidades e discutir os elementos culturais, o papel da mídia, a evolução das regras, etc. (MACHADO; GALATTI; PAES, 2015).

Portanto, os referenciais são balizadores de conjuntos de conteúdos que podem - e devem - ser desenvolvidos intencionalmente ao longo do processo pedagógico. Segundo Machado (2012, p. 103), "embora existam semelhanças entre as propostas dos Referenciais da PE e as três dimensões do conteúdo, na prática elas se manifestam de formas diferentes". Para tanto, passaremos a compreender o que são, efetivamente, os conteúdos e suas dimensões. 
Referenciais da pedagogia do esporte e as dimensões dos conteúdos: interfaces teóricas... Thiago José Leonardi • Artur Goulart Berger • Guy Ginciene • André Luís Ruggiero Barroso • Roberto Rodrigues Paes

\title{
Conteúdos e suas dimensões
}

O conceito de conteúdo, conforme alerta Darido (2012, p. 51), "é tão utilizado quanto mal compreendido". Segundo a autora, ao tratarmos dos conteúdos estamos

\begin{abstract}
englobando conceitos, ideias, fatos, processos, princípios, leis científicas, regras, habilidades cognoscitivas, modos de atividade, métodos de compreensão e aplicação, hábitos de estudos, de trabalho, de lazer e de convivência social, valores, convicções e atitudes (p. 52).
\end{abstract}

Tomando por base os referenciais da Pedagogia do Esporte destacados anteriormente, podemos pensar em uma ampla gama de conteúdos que podem fazer parte de um processo pedagógico. Esses conteúdos precisam ser organizados desde o início do planejamento, momento em que, a partir das características de cenário, personagens e modalidade, são definidos objetivos a serem alcançados (PAES; BALBINO, 2009). Esses objetivos, previamente definidos, darão luz aos conteúdos a serem desenvolvidos ao longo do processo pedagógico. Cada conteúdo, portanto, abordado à luz da Pedagogia do Esporte e sua constante preocupação com a práxis (fazer concreto, relação entre teoria e prática) (PIMENTA, 2002; FERREIRA, 2009), carrega consigo dimensões que transcendem uma visão reduzida de sua aplicação no contexto esportivo.

O conceito de dimensões dos conteúdos advém da educação e não especificamente da educação física ou do esporte. Quando foram propostas, as dimensões tinham como pressuposto romper com o conceito simplificado de conteúdo regente até o momento, indo para além das capacidades cognitivas dos alunos, com o intuito de contemplar outras capacidades como: motoras, afetivas, de relação interpessoal e de inserção social (ZABALA, 1998). Para tanto, Coll et al. (2000) propõem as dimensões conceitual, procedimental e atitudinal, às quais Zabala (1998) associa, respectivamen- 
Referenciais da pedagogia do esporte e as dimensões dos conteúdos: interfaces teóricas... Thiago José Leonardi • Artur Goulart Berger • Guy Ginciene • André Luís Ruggiero Barroso • Roberto Rodrigues Paes

te, as seguintes questões: "o que se deve saber?", "o que se deve saber fazer?", "como se deve ser?". Barroso e Darido (2009, p. 282) indicam que "as primeiras obras estruturadas na perspectiva da organização dos conteúdos apareceram por meio dos Parâmetros Curriculares Nacionais, a partir de 1997".

Segundo os Parâmetros Curriculares Nacionais (BRASIL, 1997, p. 51), os conteúdos localizados dentro da dimensão conceitual fazem referência à "construção ativa das capacidades intelectuais para operar com símbolos, ideias, imagens e representações que permitem organizar a realidade". Barroso (2008) faz a conexão entre a dimensão conceitual e as aulas de esporte, e comenta que ao ensinar um esporte, o professor/treinador deve promover um entendimento do coletivo relacionado ao surgimento e as transformações desse jogo ou modalidade esportiva, proporcionando condições para que os alunos reflitam acerca dos "diferentes contextos, possibilidades e abrangências do esporte" além de oportunizar momentos para se refletir e dialogar sobre valores e atitudes durante a vida (BARROSO, 2008, p. 53). Darido (2012) acrescenta que as transformações dos hábitos de vida na sociedade contemporânea, a importância da atividade física, além das corretas formas de execução de exercícios e das práticas corporais cotidianas são exemplos de conteúdo posicionados na dimensão conceitual.

A segunda dimensão dos conteúdos é a procedimental. Os Parâmetros Curriculares Nacionais (BRASIL, 1997) relacionam os conteúdos dessa dimensão com o "saber fazer", elementos que se fazem presentes em projetos e atividades em que a tomada de decisão e a realização de ações ordenadas na busca por um objetivo são estimulados. Aproximando esse conceito da Educação Física, segundo Barroso (2008), os elementos procedimentais do esporte se manifestam na dinâmica de uma partida, na realização dos fundamentos técnicos e táticos envolvidos e a aprendizagem dos movimentos básicos das modalidades esportivas. A Base Nacional Comum Curricular (BRASIL, 2018, p. 13) "atualiza" a definição do "saber fazer", indicando que o enfoque pedagógico para o ensino no ensino fundamental e médio - não apenas na Educação Física 
Referenciais da pedagogia do esporte e as dimensões dos conteúdos: interfaces teóricas... Thiago José Leonardi • Artur Goulart Berger • Guy Ginciene • André Luís Ruggiero Barroso • Roberto Rodrigues Paes

- deve se considerar a "mobilização desses conhecimentos, habilidades, atitudes e valores para resolver demandas complexas da vida cotidiana, do pleno exercício da cidadania e do mundo do trabalho".

A dimensão atitudinal, segundo os Parâmetros Curriculares Nacionais (BRASIL, 1997, p. 52), está presente em todo ambiente e conhecimentos desenvolvidos dentro do contexto escolar, visto que a escola é um espaço "socializador, gerador de atitudes relativas ao conhecimento, ao professor, aos colegas, às disciplinas, às tarefas e à sociedade". O mesmo documento destaca ainda que são conteúdos dessa dimensão as atitudes, os valores e as normas. Barroso e Darido (2009, p. 287) orientam que a prática pedagógica dos esportes, na dimensão atitudinal, deve promover uma

formação que busque a autonomia, para a qual são salientados valores e condutas de comportamentos como participação, socialização, coeducação, respeito, cooperação, emancipação, igualdade e convivência.

Mesquita (2006) destaca ainda a socialização esportiva, a participação ativa, a cooperação entre os pares, em um ambiente que privilegia o respeito às diferenças individuais, a igualdade de possibilidades, buscando sempre a presença da ética e da moral nas ações do professor, pois, como orienta Freire (1996, p. 33), "o ensino dos conteúdos não pode dar-se alheio à formação moral do educando".

Segundo Darido (2012), embora possa haver ênfase em determinada dimensão, é preciso alertar que, na prática docente, não há como dividir os conteúdos na dimensão conceitual, atitudinal e procedimental, dado que se manifestam de maneira inter-relacionada. Da mesma forma, considerando o esporte como um fenômeno sociocultural, embora possamos dar ênfase a determinado referencial da Pedagogia do Esporte no seu desenvolvimento no contexto aplicado, os referenciais estão igualmente interligados. Como, então, entender de forma mais aprofundada as interfaces 
Referenciais da pedagogia do esporte e as dimensões dos conteúdos: interfaces teóricas... Thiago José Leonardi • Artur Goulart Berger • Guy Ginciene • André Luís Ruggiero Barroso • Roberto Rodrigues Paes

entre os referenciais da Pedagogia do Esporte e as dimensões dos conteúdos? Barroso e Darido (2009) fizeram um primeiro exercício acerca dessa associação quando dividiram suas reflexões em "iniciação esportiva: dimensão procedimental" e "formação humana: dimensão conceitual e procedimental", refletindo no contexto da Educação Física escolar. Faremos, a seguir, um novo exercício de reflexão, ampliando e atualizando o debate realizado pelos autores para além das fronteiras escolares, tendo por base o conceito de Pedagogia do Esporte e os múltiplos sentidos e possibilidades que podem ser alcançados por meio da atuação dos agentes pedagógicos independentemente do cenário no qual atuem.

\section{Interfaces entre referenciais, conteúdos e dimensões}

Para iniciar nossa reflexão sobre o tema, tentaremos responder à questão posta ao final da introdução: São eles (referenciais e dimensões dos conteúdos) propostas semelhantes ou podemos interpretá-los como conceitos distintos, porém interligados? A resposta a essa pergunta exige de professores e pesquisadores um olhar teórico com aplicação prática. Conforme destacado neste ensaio, ambos (referenciais e dimensões) foram criados para ampliar o conceito do que ensinar: os referenciais buscaram superar a ideia de sustentar o ensino nas questões, sobretudo técnicas e táticas ou metodológicas, dos esportes (PAES, 1996), enquanto as dimensões dos conteúdos, inicialmente no contexto ampliado da educação, buscaram superar a ênfase no desenvolvimento das capacidades cognitivas (dimensão conceitual) dos alunos na escola (ZABALA, 1998), sendo que na Educação Física brasileira o objetivo era superar a prevalência do "saber fazer", ou seja, da dimensão procedimental (DARIDO, 2012). Em um primeiro olhar, no tocante ao esporte, ambos, referenciais e dimensões, surgiram no esforço de superar a mera execução de elementos técnicos (ou o "saber fazer"). A superação desse reducionismo exige considerar a existência de outros referenciais e outras dimensões dos conteúdos e 
Referenciais da pedagogia do esporte e as dimensões dos conteúdos: interfaces teóricas... Thiago José Leonardi • Artur Goulart Berger • Guy Ginciene • André Luís Ruggiero Barroso • Roberto Rodrigues Paes

mais, considerar a interface complexa entre eles. Como solucionar esse impasse teórico?

Primeiro, precisamos compreender que ambos, referenciais e dimensões, foram originalmente propostos como norteadores para a definição dos conteúdos a serem ensinados. Em outras palavras, ambos podem contribuir para dar tratamento pedagógico aos conteúdos do Esporte, e se somam ao permitir interface e aplicação em diferentes cenários de atuação. Contudo, embora nascidos com um mesmo propósito, não podem ser tratados como equivalentes, pois, na essência, são complementares. Discorreremos sobre essa interface a partir do exemplo a seguir, que está centrado nas etapas de planejamento e de organização dos conteúdos, as quais são inerentes à prática pedagógica. Acrescentamos que o exercício reflexivo descrito abaixo indica uma possibilidade de ilustração de como a intencionalidade por detrás da descrição de um objetivo, no planejamento, pode direcionar o foco para que identifiquemos com maior clareza a interface entre referenciais e dimensões e, a partir disso, consigamos elaborar melhores aulas que direcionem os olhares de nossos(as) alunos(as) ou atletas para aquilo que de fato queremos que aprendam ou aprimorem.

Durante o planejamento do processo pedagógico é indicado que sejam listados os objetivos que se almeja alcançar em determinado período. Esses objetivos pressupõem que algo precisará ser ensinado e direcionam (intencionalmente) um determinado foco para qual (ou quais) conteúdo(s) serão desenvolvidos. Aqui começa um primeiro impasse teórico entre as teorias de base entre referenciais da Pedagogia do Esporte e as Dimensões dos Conteúdos: o que efetivamente é tratado como conteúdo? Quando olhamos para a teoria das dimensões dos conteúdos, criadas para o contexto educacional, os conteúdos abordados são, a priori, mais amplos. Na interface específica com a Educação Física Escolar, o esporte em si seria um dos conteúdos a serem abordados e as modalidades esportivas, por exemplo, segundo a Base Nacional Comum Curricular (BRASIL, 2018), deveriam ser agrupadas por sua lógica interna ou mesmo abordadas de maneira separada, como 
Referenciais da pedagogia do esporte e as dimensões dos conteúdos: interfaces teóricas... Thiago José Leonardi • Artur Goulart Berger • Guy Ginciene • André Luís Ruggiero Barroso • Roberto Rodrigues Paes

"conteúdos específicos", respeitando a característica do currículo escolar.

Em linhas gerais, podemos interpretar que a Pedagogia do Esporte assume como conteúdos os elementos que constituem o esporte, em cada um dos referenciais, dando enfoque mais específico ao que vai ser trabalhado em aula (e aqui entram os conteúdos advindos dos referenciais). Ao discutir o planejamento, a Pedagogia do Esporte entende que conhecer a modalidade é um dos pressupostos (junto com o cenário, os personagens e os objetivos) para se trilhar a organização do que será ensinado (conteúdos), conforme abordam Balbino e Paes (2005). Nessa perspectiva, a Pedagogia do Esporte se apresenta como uma ciência que pode colaborar no processo pedagógico de ensino dos esportes também na escola, auxiliando, inclusive, na melhor definição dos conteúdos específicos a serem desenvolvidos a partir da lógica ou das modalidades a serem desenvolvidas em determinado período do currículo escolar.

Segundo impasse teórico: como abordar os três referenciais e as três dimensões de conteúdo? É possível "separá-los" ao longo do processo pedagógico? A resposta a essa pergunta exige um olhar direcionado à simbiose necessária entre teoria e prática, que podemos chamar de práxis (PIMENTA, 2002). A princípio, podemos entender que tanto os referenciais técnico-tático, socioeducativo e histórico-cultural quanto as dimensões conceitual, procedimental e atitudinal coexistem no fenômeno esporte, independentemente da modalidade a ser abordada. Mas como desenvolvê-los em aula? Embora exista a coexistência, é possível levar o foco da aula a um ou mais desses elementos. Abordaremos esse aspecto a partir de um exercício teórico que objetiva trazer um exemplo de como direcionar o foco, sem perder de vista que os demais referenciais e dimensões também interagem para a construção e significação do conhecimento. Suponhamos que somos professores(as) ou treinadores(as) de alguma modalidade esportiva coletiva de invasão (GONZÁLEZ; BRACHT, 2012), trabalhando com adolescentes de 12 anos de idade, e que em nosso planejamento tenhamos como ob- 
Referenciais da pedagogia do esporte e as dimensões dos conteúdos: interfaces teóricas... Thiago José Leonardi • Artur Goulart Berger • Guy Ginciene • André Luís Ruggiero Barroso • Roberto Rodrigues Paes

jetivo ensinar a manutenção da posse da bola (conteúdo presente na lógica interna dessas modalidades).

Em nosso planejamento, definimos que em determinado momento daremos ênfase nas ações dos atacantes sem a posse da bola e, para isso, definimos como conteúdo a criação de linha de passe. Mas, o que de fato precisaremos ensinar? Não pretendemos esgotar o assunto, mas apenas contribuir para o exercício teórico de reflexão. Em linhas gerais, notamos, num primeiro olhar, um conteúdo técnico-tático, em que será necessário abordar a dimensão conceitual sobre o que é manter a posse da bola e o que é e como criar linha de passe; disso irá emergir a dimensão procedimental, aliando a intenção à ação; emergirão, ainda, relações com a dimensão atitudinal, associando condutas e comportamentos necessários para a concretização daquela ação.

Note-se que, nessa perspectiva, seria possível associar também, com maior ou menor ênfase, conteúdos socioeducativos (como as atitudes necessárias para jogar poderão ser dialogadas na interface com a vida na comunidade), bem como histórico-culturais (evolução da ação de criação de linha de passe na história e na cultura de determinada modalidade, bem como o impacto dessa ação na dinâmica do jogo). Mas, por onde começar? A resposta pode ser sintetizada em uma palavra: depende! Em síntese, depende do cenário, dos personagens e dos objetivos traçados para aquele período de aulas. Isso influenciará, inclusive, que em uma aula (ou conjunto de aulas) alguns referenciais e dimensões sejam mais ou menos evidenciados, e desse aspecto advém a riqueza e a complexidade do processo pedagógico.

Tentamos ilustrar a complexidade do exposto nesse exemplo por meio da figura 1. Podemos observar nela que todos os referenciais e dimensões estão interligados, mas que ao ministrar os conteúdos (exemplificamos a partir da criação de linha de passe) podemos dar ênfase maior em alguma aula a determinado referencial e a determinada dimensão (daí a linha de passe estar deslocada do centro da figura, por ter maior prevalência do referencial técnico tático, sobretudo na interface entre as dimensões 
Referenciais da pedagogia do esporte e as dimensões dos conteúdos: interfaces teóricas... Thiago José Leonardi • Artur Goulart Berger • Guy Ginciene • André Luís Ruggiero Barroso • Roberto Rodrigues Paes

procedimental e conceitual), com a ressalva de que a compreensão do fenômeno esporte em si é maior do que somar cada parte (referencial/dimensão/conteúdo). Por isso, a figura mostra a interligação entre cada referencial e dimensão, reserva um espaço para o que poderia em algum momento ser abordado "de forma separada" em cada referencial e em cada dimensão, e ainda possui espaços "em branco", não preenchidos por nenhum referencial nem dimensão, de forma que o todo pudesse "exceder" a soma das partes.

Figura 1 - Relação entre referenciais da Pedagogia do Esporte e as dimensões dos conteúdos, exemplificando o conteúdo criação de linha de passe

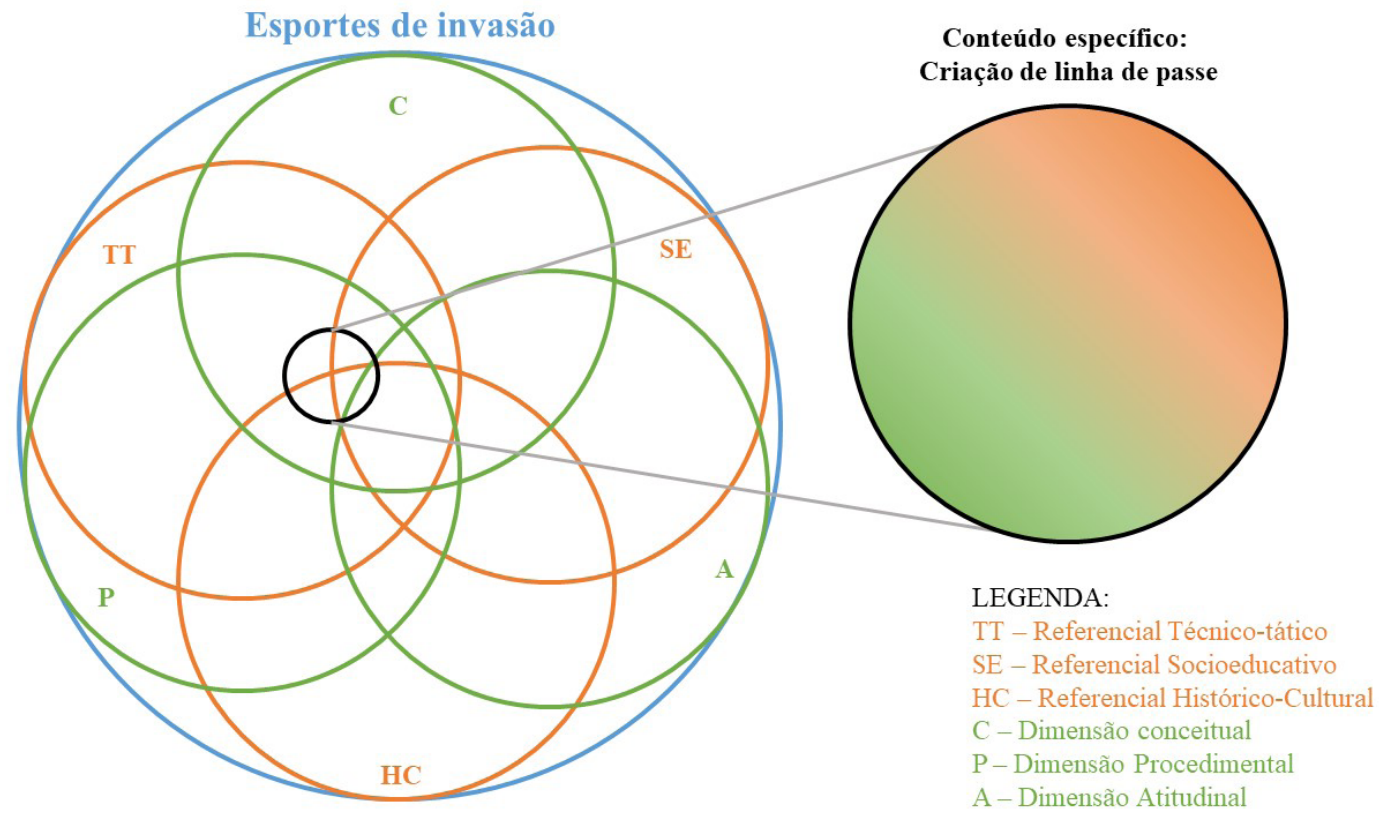

Fonte: os autores.

Nota-se no exemplo e na figura acima, portanto, que quando observamos questões específicas do esporte, no dia a dia da atuação pedagógica de professores e treinadores, os referenciais e as dimensões, se entendidas como partes, integram-se, mas não totalizam por si só, o conteúdo em questão. Na teia complexa de conhecimentos necessários para jogar uma modalidade esportiva (SANTANA, 2005), conceitos, procedimentos e atitudes entrela- 
Referenciais da pedagogia do esporte e as dimensões dos conteúdos: interfaces teóricas... Thiago José Leonardi • Artur Goulart Berger • Guy Ginciene • André Luís Ruggiero Barroso • Roberto Rodrigues Paes

çam-se, sem se isolar, assim como os diferentes referenciais entre si e com aqueles, para formar um emaranhado de conteúdos gerais e específicos que fazem o todo ser mais do que a soma das partes (Figura 1). Nessa perspectiva, cabe ao professor, seguindo o seu planejamento, definir onde estará intencionalmente o foco de sua aula, permitindo aos seus alunos que também atentem-se àquele(s) aspecto(s). Reforçamos, portanto, que o exercício de reflexão acima não teve como premissa reduzir o conteúdo a partes menores, mas abordar um exemplo de como pode ser interpretada a relação entre referenciais e dimensões dos conteúdos, a fim de auxiliar professores e treinadores a visualizar, em sua atuação, formas intencionais de aprofundar nos elementos constituintes dos conteúdos que venham a ser ministrados.

Imaginemos agora, como exemplo adicional, uma aula de atletismo na Educação Física escolar, cujo conteúdo selecionado está dentro do referencial histórico-cultural: as transformações históricas das corridas de velocidade do atletismo (GINCIENE; MATTHIESEN, 2009). Embora esse conteúdo pareça demandar uma aula teórica e explicativa, é válido ressaltar que ele não possui apenas dimensão conceitual. Sua dimensão procedimental poder ser ensinada em articulação com as dimensões conceituais e atitudinais, conforme explicitado em Ginciene e Matthiesen (2009). Nessa perspectiva, portanto, os(as) alunos(as) podem vivenciar as transformações das corridas de velocidade na prática, à medida que experimentam as diferentes formas de saída (em pé, como no início dos Jogos Olímpicos, até a saída baixa atual), as diferentes formas de corrida (sem raia, como na Grécia Antiga, até a corrida com raias, na atualidade) e as diferentes formas de chegada (sem marcação de tempo e com marcação de tempo com cronômetro e photo finish) ao passo que o(a) professor(a) vai contando e problematizando as transformações que as corridas de velocidade passaram no decorrer de sua história (GINCIENE; MATTHIESEN, 2009). Nessa mesma aula, ainda é possível abordar conteúdos (a) técnico-táticos e (b) socioeducativos, por exemplo: (a) ensinar a técnica da saída baixa enquanto os alunos vivenciam o percurso histórico 
Referenciais da pedagogia do esporte e as dimensões dos conteúdos: interfaces teóricas... Thiago José Leonardi • Artur Goulart Berger • Guy Ginciene • André Luís Ruggiero Barroso • Roberto Rodrigues Paes

das corridas; (c) abordar a questão do respeito como tema transversal de toda aula e, com isso, tratar a dimensão atitudinal das corridas com e sem raias.

\section{Considerações finais}

Encontrar interfaces entre os referenciais da Pedagogia do Esporte e as dimensões dos conteúdos pode auxiliar professores e treinadores em sua atuação profissional. Isso se dá à medida que passam a visualizar com maior clareza qual o conteúdo que estão desenvolvendo e qual (ou quais) das dimensões daquele conteúdo estão a enfatizar em determinada aula ou atividade. Nesse sentido, este ensaio buscou elucidar que (i) referenciais, conteúdos e dimensões coexistem mutuamente no processo pedagógico; (ii) os referenciais (técnico-tático, socioeducativo e histórico-cultural) e as dimensões (conceitual, procedimental e atitudinal) podem ser compreendidos como norteadores para a definição dos conteúdos (gerais e específicos) que serão desenvolvidos em uma aula ou conjunto de aulas e (iii) ao longo do processo pedagógico é natural que o professor ou treinador chame a atenção de seus alunos ou atletas para determinado referencial e/ou dimensão do conteúdo em aulas específicas, mas a compreensão da interação complexa e de complementaridade desses elementos pode potencializar o alcance dessa prática pedagógica. Com isso, a atuação pedagógica, embora considerando a complexidade inerente à prática esportiva, tenderá a ter sua intencionalidade mais evidenciada, tornando o processo mais claro para todos os sujeitos envolvidos nesse contexto.

\section{Referências}

BALBINO, H. F.; PAES, R. R. Pedagogia do esporte e os jogos esportivos coletivos na ótica das inteligências múltiplas. In: PAES, 
Referenciais da pedagogia do esporte e as dimensões dos conteúdos: interfaces teóricas... Thiago José Leonardi • Artur Goulart Berger • Guy Ginciene • André Luís Ruggiero Barroso • Roberto Rodrigues Paes

R. R.; BALBINO, H. F. (Org.). Pedagogia do Esporte: contextos e perspectivas. Rio de Janeiro: Guanabara Koogan, 2005.

BARROSO, A. L. R. Voleibol escolar: uma proposta de ensino nas três dimensões dos conteúdos. 2008. 226f. 2008. Tese de Doutorado. Dissertação (Mestrado em Ciências da Motricidade) Instituto de Biociências, Universidade Estadual Paulista, Rio Claro. BARROSO, A. L. R.; DARIDO, S. C: A Pedagogia do Esporte e as Dimensões dos Conteúdos: Conceitual, Procedimental e Atitudinal. Revista da Educação Física /UEM. Maringá, v. 20, nº 2, p. $281-289,2^{\circ}$ trim., 2009.

BRASIL. Lei de Diretrizes e Bases da Educação Nacional, LDB. 9394/1996.

BRASIL. Ministério de Educação e Cultura. Secretaria de Ensino Fundamental. Parâmetros curriculares nacionais: Educação Física. Brasília, DF, 1997.

BRASIL, Ministério da Educação e Cultura. Base Nacional Comum Curricular - BNCC. Brasília, 2018.

COLL, C. et al. Os conteúdos na reforma: ensino e aprendizagem de conceitos, procedimentos e atitudes. Porto Alegre: Artmed, 2000 .

DARIDO, S. C. Os conteúdos da Educação Física na escola. In: DARIDO, S. C.; RANGEL, I. C. A. Educação Física na escola. Rio de Janeiro: Guanabara Koogan, 2005.

DARIDO, S. C. Educação física na escola: conteúdos, suas dimensões e significados. UNIVERSIDADE ESTADUAL PAULISTA. Prograd. Caderno de formação: formação de professores didática geral. São Paulo: Cultura Acadêmica, p. 51-75, 2012. ELIAS, N.; DUNNING, E. A busca da excitação. Lisboa: Difusão, 1992.

FERREIRA, H. B. Pedagogia do esporte: identificação, discussão e aplicação de procedimentos pedagógicos no processo de ensino-vivência aprendizagem da modalidade basquetebol. 
Referenciais da pedagogia do esporte e as dimensões dos conteúdos: interfaces teóricas... Thiago José Leonardi • Artur Goulart Berger • Guy Ginciene • André Luís Ruggiero Barroso • Roberto Rodrigues Paes

2009. 259 p. Dissertação (mestrado) - Universidade Estadual de Campinas, Faculdade de Educação Física, Campinas, SP.

FREIRE, J. B. Pedagogia do futebol. Campinas: Autores Associados, 2002.

GALATTI, L. R. Pedagogia do esporte: esporte e clube sócio-esportivo: percurso, contextos e perspectivas a partir de estudo de caso em clube esportivo espanhol. 2010. Tese (Doutorado em Educação Física) - Faculdade de Educação Física, Universidade Estadual de Campinas, Campinas, 2010.

GALATTI, L. R. et al. Pedagogia do esporte: tensão na ciência e o ensino dos jogos esportivos coletivos. Revista da Educação Física/UEM, v. 25, n. 1, p. 153-162, 2014.

GALATTI, L. R. et al. O ensino dos jogos esportivos coletivos: avanços metodológicos dos aspectos estratégico-tático-técnicos. Pensar a prática, v. 20, n. 3, 2017.

GINCIENE, G.; MATTHIESEN, S. Q. Fragmentos da história dos 100 metros rasos: teoria e prática. Coleção Pesquisa em Educação Física, v. 8, p. 181-186, 2009.

GONZÁLEZ, F. J. Projeto curricular e educação física: o esporte como conteúdo escolar. In: REZER, R. (Org.). $O$ fenômeno esportivo: ensaios crítico-reflexivos. Chapecó: Argos, 2006. p. 69-109. GONZÁLEZ, F. J.; BRACHT, V. Metodologia do ensino dos esportes coletivos. Vitória: UFES, Núcleo de Educação Aberta e a Distância, 2012.

GUTTMANN, A. From ritual to record: the nature of modern sports. New York: Columbia University, 1978.

LEONARDI, T. J. et al. Pedagogia do esporte: indicativos para o desenvolvimento integral do indivíduo. Revista Mackenzie de Educação Física e Esporte, São Paulo, v. 13, n. 1, p. 41-58, ago. 2014.

LEONARDI, T. J. et al. Pedagogia do Esporte: sinalização para a avaliação formativa da aprendizagem. Pensar a Prática, Goiânia, v. 20, n. 1, 2017. 
Referenciais da pedagogia do esporte e as dimensões dos conteúdos: interfaces teóricas... Thiago José Leonardi • Artur Goulart Berger • Guy Ginciene • André Luís Ruggiero Barroso • Roberto Rodrigues Paes

LEONARDI, T. J.; BERGER, A. G.; REVERDITO, R. S. Esporte contemporâneo e os novos desafios à pedagogia do esporte. In: Esporte e sociedade: um olhar a partir da globalização. São Paulo, SP: lea/USP, 2019. p. 254-269. 2019.

MACHADO, G. V. Pedagogia do esporte: organização, sistematização, aplicação e avaliação de conteúdos esportivos na educação não formal. 2012. Dissertação (Mestrado em Educação Física) - Faculdade de Educação Física, Universidade Estadual de Campinas, Campinas, 2012.

MACHADO, G. V.; GALATTI, L. R.; PAES, R. R. Pedagogia do Esporte e o Referencial Histórico-cultural: interlocução entre teoria e prática. Pensar a Prática, Goiânia, v. 17, n. 2, p. 414-430, jan./ mar. 2014.

MACHADO, G. V.; GALATTI, L. R.; PAES, R. R. Pedagogia do esporte e projetos sociais: interlocuções sobre a prática pedagógica.

Revista Movimento, Porto Alegre, v. 21, n. 2., p. 405-418, abr./jun. de 2015

MEDINA, J. P. S. Educação física cuida do corpo... e" mente". Papirus Editora, 1983.

MESQUITA, I. Ensinar bem para aprender melhor o jogo de voleibol. In: TANI, G; BENTO, J. O.; DE SOUZA PETERSEN, R. D. (Ed.). Pedagogia do desporto. Guanabara Koogan, 2006. p. 327-344. OLIVEIRA, A. B. de et al. (Org.). Ensinando e aprendendo esportes no Programa Segundo Tempo. Maringá: Eduem, 2011. 2v. $(432,356$ p.)

PAES, R. R. Educação Física Escolar: O esporte como conteúdo pedagógico do ensino fundamental. 1996. Tese (Doutorado em Educação), Universidade Estadual de Campinas, Campinas, 1996.

PAES, R. R.; BALBINO, H. F. A pedagogia do esporte e os jogos coletivos. DE ROSE, D. et al. Esporte e atividade física na infância e adolescência: uma abordagem multidisciplinar. Porto Alegre: Artmed, p. 73-83, 2009. 
Referenciais da pedagogia do esporte e as dimensões dos conteúdos: interfaces teóricas... Thiago José Leonardi • Artur Goulart Berger • Guy Ginciene • André Luís Ruggiero Barroso • Roberto Rodrigues Paes

PIMENTA, S. G.(Org.). Pedagogia e pedagogos: caminhos e perspectivas. São Paulo: Cortez, 2002.

REVERDITO, R. S.; SCAGLIA, A. J.; PAES, R. R. Pedagogia do esporte: panorama e análise conceitual das principais abordagens. Motriz, v. 15, n. 3, p. 600-610, 2009.

SANTANA, W. C. Pedagogia do esporte na infância e complexidade. PAES, R. R.; BALBINO, H. F. Pedagogia do esporte: contextos e perspectivas. Rio de Janeiro: Guanabara Koogan, p. 1-24, 2005.

SCAGLIA, A. J. 0 futebol que se aprende e o futebol que se ensina. 1999. 242. f. Dissertação (Mestrado em Educação Física) - Faculdade de Educação Física. Universidade Estadual de Campinas. Campinas, 1999.

SEVERINO, A. J. Metodologia do trabalho científico. 21 ed. São Paulo: Cortez, 2000.

ZABALA, A. A prática educativa: Como ensinar. Porto Alegre: Artmed, 1998.

\section{Publisher}

Universidade Federal de Goiás. Faculdade de Educação Física e Dança. Publicação no Portal de Periódicos UFG. As ideias expressadas neste artigo são de responsabilidade de seus autores, não representando, necessariamente, a opinião dos editores ou da universidade. 